\title{
La Saliva, Flujo y Ph en relación a la Actividad Cariogenica
}

The Saliva Flow In Relation

To Ph Caries Activity

O Fluxo Saliva Em Relação

A Atividade de Cárie Y Ph

Fecha de Recepción

I7 de octubre de 20 | |
Aceptado para su publicación

02 de diciembre de 20 I I
Carolina Elizabet Barrios

Docente Auxiliar Cátedra Práctica Clínica

Preventiva I. FOUNNE.

E-mail: caroliebarrios@hotmail.com

Vilma Graciela Vila

Profesor Titular Cátedra Práctica

Clínica Preventiva I. FOUNNE.

Sandra Elena Martínez

Profesor Adjunto Cátedra Práctica Clinica Preventiva I. FOUNNE

Alejandro Joaquín Encina Tutuy

Becario de Investigación en Iniciación SGCYT. FOUNNE

\section{Resumen}

La caries dental es una enfermedad infectocontagiosa de etiología multifactorial que produce una infección final destructiva sobre el esmalte, la dentina y el cemento dentario; puede afectar a cualquier persona y es la causa más importante de la pérdida de dientes en los más jóvenes.

La caries dental puede ser detectada en un examen clínico de rutina presentándose sobre el esmalte de los dientes, como manchas blancas que con el avance del tiempo puede llegar a causar pequeñas fracturas o cavidades.

La aparición y progreso de la caries se debe a la intervención de varios factores etiológicos imprescindibles para que se inicie la lesión, como la microbiota local representada por las bacterias acidogénicas, el huésped representado por la saliva y los dientes, la dieta rica en azucares y harinas, $y$ el tiempo, que permite esclarecer de una forma más precisa la formación de esta enfermedad.

La saliva estabiliza el pH por su concentración de carbonatos $y$ fosfatos $y$ cuando la higiene bucal es deficiente, el pH es ácido y óptimo para desmineralizar las superficies dentarias con un alto riesgo del inicio de caries.

\section{Palabras Claves}

Flujo, pH, saliva, caries.

\section{Summary}

The caries dental is an infected - contagious disease of etiology multifactorial that produces 
a final destructive infection on the enamel, the dentine and the cement toothwort; it can affect any person and is the most important reason of the loss of teeth in the youngest The caries dental can be detected in a clinical examination of routine appearing on the enamel of the teeth, as white spots that with the advance of the time it can manage to cause small fractures or cavities.

The appearance and progress of the caries owes to the intervention of several factors etiológicos indispensable in order that the injury begins, as the local microbiota represented by the bacteria acidogénicas, the guest represented by the saliva and the teeth, the rich diet in sweeten and flours, and the time, which allows to clarify of a more precise form the formation of this disease. The saliva stabilizes the $\mathrm{pH}$ for his concentration of carbonates and phosphates and when the mouth hygiene is deficient, the $\mathrm{pH}$ is acid and ideal to demineralize the surfaces dentarias with a high risk of the beginning of caries.

\section{Keywords}

Flow, $\mathrm{pH}$, saliva, caries.

\section{Resumo}

A caries dental é uma doença infecciosa de etiología multifactorial que produz uma infecção final destructiva sobre o esmalte, a dentina e o cemento dentario. A caries dental pode ser detectada num exame de rutina sobre o esmalte dos dentes como manchas brancas que com o avanço do tempo pode chegar a causar pequenas fracturas ou cavidades.

O aparecimento e progresso da caries deve-se à intervenção de vários factores imprescindibles para que se inicie a lesão. Ditos factores são a microbiota local representada pelas bactérias acidogénicas, o hóspede representado pela saliva e os dentes, a dieta de acordo à ingesta de carbohidratos e o tempo, que permitiu esclarecer de uma forma mais precisa a formação da caries dental.

No estudo das causales que influem no desenvolvimento da caries se deve ter presente a participação de múltiplos factores que actuam como método preventivo das doenças prevalentes da cavidad bucal.

\section{Palavras chave}

Fluxo, pH, saliva, cárie.

\section{Introducción}

La saliva es un fluido compuesto de moléculas complejas que protegen a los tejidos blandos, controla la sequedad y puede influir en la reparación de los tejidos'.

Si bien la cantidad de saliva es importante, también lo es la calidad de la misma, ya que cada uno de sus componentes desempeña una serie de funciones específicas ${ }^{2}$.

La secreción salival juega un papel importante en la homeostasis, los mecanismos fisiológicos y la composición molecular de la saliva, contribuyendo al mecanismo de defensa para la salud buco dental ${ }^{3}$.

La cantidad adecuada de flujo salival favorece la eliminación de sustratos bacterianos y protege las superficies bucales. El flujo salival está sujeto a una serie de cambios producidos por la ingesta de alimentos, el ritmo circadiano, la edad, el género, los que de alguna manera modifican la normalidad de los tejidos bucales favoreciendo entre otras patologías la incidencia de caries dental ${ }^{4}$.

\section{Desarrollo}

\section{La Saliva: Componentes y Funciones}

La saliva es una secreción compleja proveniente de las glándulas salivales mayores en el $93 \%$ de su volumen y de las menores en el $7 \%$ restante, las cuales se extienden por todas las regiones de la boca excepto en la encía y en la porción anterior del paladar duro. Es estéril cuando sale de las glándulas salivales, pero deja de serlo inmediatamente cuando se mezcla con el fluido crevicular, restos de alimentos, microorganismos, células descamadas de la mucosa oral, etc ${ }^{5}$.

La secreción diaria oscila entre 500 y $700 \mathrm{ml}$, con un volumen medio de $\mathrm{I}, \mathrm{I} \mathrm{ml}$., en reposo entre 0,25 y $0,35 \mathrm{ml} / \mathrm{min}$., y ante estímulos sensitivos, eléctricos o mecánicos hasta $1,5 \mathrm{ml} / \mathrm{mn}$., aunque el mayor volumen salival se produce antes, durante y después de las comidas con un pico máximo alrededor de las 12 del mediodía, disminuyendo en forma considerable por la noche, durante el sueño, producción controlada por el sistema nervioso autónomo'. 
En su composición el $99 \%$ es agua mientras que el I\% restante está compuesto por moléculas orgánicas e inorgánicas. La saliva es un fluido compuesto de moléculas complejas que influyen en la reparación de los tejidos blandos controlando la sequedad. También es un buen indicador de los niveles plasmáticos de hormonas y drogas, por lo que puede utilizarse como método no invasivo para monitorizar las concentraciones plasmáticas de medicamentos u otras sustancias ${ }^{7}$.

Si bien la cantidad de saliva es importante, también lo es la calidad de la misma, ya que cada uno de sus componentes desempeña una serie de funciones específicas ${ }^{8}$.

La cantidad normal de saliva puede verse disminuida, afectando de manera significativa a la calidad de vida de un individuo así como a su salud bucal, se habla entonces de hiposalivación, caracterizada por la manifestación de múltiples signos y síntomas, incluyendo alteraciones clínicas en la viscosidad salival, superficie lingual depapilada roja, sensación de boca seca, sed frecuente, dificultad para tragar, para hablar y comer alimentos secos y disgeusia, pérdida del brillo de la mucosa oral, fisuras en el dorso de la lengua, queilitis angular, saliva espesa y aumento de la frecuencia de infecciones orales 9.10 .

La saliva posee múltiples funciones de carácter digestivo, favoreciendo a la formación del bolo digestivo facilitando la masticación y deglución, también beneficia la protección tejidos blandos bucales evitando la desecación y permeabilidad contribuyendo a la reparación. A nivel de tejidos duros permite un intercambio de $\mathrm{Ca}$ y fosfato con el esmalte, acción hidrocinética de limpieza, mantenimiento de un $\mathrm{pH}$ adecuado y acción antimicrobiana".

\section{Flujo Salival: Su relación con caries dental}

Se considera que el papel que juega la saliva contra la caries dental es principalmente por la cantidad de flujo ya que este favorece la limpieza de sustratos bacterianos y protege las superficies bucales, es decir, que una deficiente secreción salival y una saliva viscosa y espesa constituyen aspectos que favorecen una mayor incidencia de caries dental.

Por tal motivo queda comprobado que a medida que aumenta la viscosidad salival, es decir, una saliva espesa y viscosa y haya una disminución del flujo salival dará como resultado una mayor tendencia en la incidencia de formación de caries dental'2.

La tasa de flujo salival se puede obtener en condiciones de estimulación o no y se calcula dividiendo el volumen salival entre el tiempo de recolección. El promedio de la tasa de flujo salival en reposo de la saliva completa o mixta es de $0.4 \mathrm{ml} / \mathrm{min}$; mientras que para la saliva mixta estimulada con parafina es de $2 \mathrm{ml} / \mathrm{min}^{8}$. Aproximadamente 0,5 litros de saliva son secretados por día, del cual el $25 \%$ proviene de las glándulas submaxilares y un $66 \%$ proviene de las glándulas parótidas ${ }^{13}$.

La tasa de flujo salival es uno de los puntos más importantes para determinar el riesgo a la caries y la cual puede ser modificada por diferentes factores. Una tasa de flujo salival adecuada es esencial para que la salud bucal se mantenga pero este equilibrio puede interrumpirse al alterarse el balance entre el huésped y los microorganismos, dando lugar al crecimiento excesivo de las bacterias. Análogamente el sistema nervioso y ciertos factores tanto biológicos como ambientales también afectan el flujo salival'4.

En personas sanas, la tasa de flujo salival basal o no estimulada se puede ver afectada por: la edad, el ritmo circadiano, el ritmo circanual, la posición corporal, la luminosidad ambiental, la tensión, el fumar, la estimulación gustativa previa, la estimulación olfativa, la estimulación psíquica y grado de hidratación ${ }^{15}$.

Existen muchos factores que tienen influencia sobre la tasa de flujo salival estimulada, cuyo valor promedio es de $7 \mathrm{ml} / \mathrm{min}$, aproximadamente. Estos factores son: el estímulo mecánico, el vómito, los estímulos gustativo y olfativo, el tamaño de la glándula y la edad ${ }^{16}$.

El flujo salivar disminuido y la consecuente sensación de boca seca, llamada Xerostomía, puede resultar de una serie de condiciones médicas, terapias con drogas y estados emocionales, también es comúnmente encontrada en personas mayores, aunque la edad en sí no es una causa de disfunción glandular salivar. Más aún, la incidencia de condiciones médicas que influyen directa o indirectamente en el flujo salivar incrementa con la edad.

La xerostomía es más común en hombres que en mujeres, particularmente después de los 50 años de edad. Las proporciones de flujo salival no estimulado son significativamente inferiores en individuos de mayor edad que en los indivi- 
duos jóvenes. Sin embargo, los resultados de los estudios difieren para las proporciones de flujo salival no estimulado; ellos han encontrado tanto que aumenta como que disminuye con la edad ${ }^{17}$. Las mucinas y glicoproteínas de la saliva involucradas en mantener la mucosa oral saludable, también decrecen con la edad, pero ninguna correlación ha sido encontrada entre las ratas de flujo salival y las concentraciones de mucina. Se ha reportado que los individuos xerostómicos son 2.9 veces más propensos a tener caries coronal, y 3.3 veces más propensos a tener caries radiculares comparadas con los que no son xerostómicos y sin medicamentos.

\section{Capacidad amortiguadora de la saliva}

La función amortiguadora de la saliva se debe principalmente a la presencia del bicarbonato ya que la influencia del fosfato es menos extensa. La capacidad amortiguadora es la habilidad de la saliva para contrarrestar los cambios de $\mathrm{pH}$. Esta propiedad ayuda a proteger a los tejidos bucales contra la acción de los ácidos provenientes de la comida o de la placa dental, por lo tanto, puede reducir el potencial cariogénico del ambiente. Los amortiguadores funcionan convirtiendo una solución ácida $O$ alcalina altamente ionizada, la cual tiende a alterar el $\mathrm{pH}$, en una solución más débilmente ionizada (que libere pocos $\mathrm{H}+\circ \mathrm{OH}-$ ). El principal amortiguador de la saliva es el bicarbonato, cuya concentración variará de acuerdo al flujo salival; el fosfato y las proteínas también actúan como amortiguadores salivales ${ }^{18}$.

El término $\mathrm{pH}$, se utiliza para expresar la concentración de iones hidrogeniones de una solución. Las concentraciones altas de hidrogeniones corresponden a $\mathrm{pH}$ bajos y las concentraciones bajas a $\mathrm{pH}$ altos. El pH se mide en unidades potenciométricas en una escala que va de 0 a I4. Existen sistemas capaces de controlar los cambios de $\mathrm{pH}$, estos se denominan sistemas de tampón o Buffer. Un sistema de tapón es una solución que contiene dos o más compuestos químicos capaces de prevenir cambios importantes de la concentración de hidrogeniones, cuando se añade un ácido o una base a la solución. Los fluidos intracelulares y extracelulares de los organismos vivos contienen pares conjugados ácido- básico los cuales actúan como tapones del pH normal de dichos fluidos. El principal tapón extracelular de los vertebrados es el sistema tapón del bicarbonato ${ }^{19}$.
Es importante en el mantenimiento del $\mathrm{pH}$, ya que posee diversos mecanismos para regular el $\mathrm{pH}$ de la placa dentobacteriana y ayuda a neutralizar el reflujo de ácidos a la cavidad bucal ${ }^{20}$. Numerosos estudios establecen la relación de la saliva con la actividad cariogenica. Mandel, realiza un estudio donde relaciona el flujo salival, en saliva estimulada y en reposo de individuos sanos con la susceptibilidad y actividad cariogénica y concluye que no hay ninguna relación importante entre estas variables y que es la condición patológica de las glándulas salivales la que puede tener una influencia en la disminución del flujo salival y la actividad de caries ${ }^{21}$.

Zengo et al., realizaron estudios entre grupos susceptibles y no a la caries con respecto a dos de los componentes antibacterianos de la saliva como son la IgA y la lactoperoxidasa, tomando la muestra de las glándulas parótida y submaxilar y concluyeron que la lgA estaba aumentada en los individuos no susceptibles a la caries ${ }^{23}$.

Billings refiere que luego de estudiar a un grupo de individuos con disminución del flujo salival, encontró que la variable edad no modificaba significativamente el flujo salival.

Nederfors en un estudio realizado en una población entre 20 y 80 años encontró que las mujeres sanas, no medicadas, presentaban una disminución significativa de flujo salival en comparación con los hombres ${ }^{24}$.

Fure señala una mayor incidencia de caries en individuos con una edad comprendida entre $60 y$ 80 años de edad donde el flujo salival estaba disminuido y el contaje de S. sobrinus estaba incrementado hasta en un $39 \%$ durante el período de estudio ${ }^{25}$.

Sin embargo, en México existen pocos estudios que relacionen a estos microorganismos y a la capacidad amortiguadora de la saliva con los índices de caries. Se sabe que el $\mathrm{pH}$ de la saliva influye en la regulación de la flora oral y que la capacidad amortiguadora tiene como función mantener el $\mathrm{pH}$ estable en la cavidad bucal. Se ha encontrado que la capacidad amortiguadora de la saliva es generalmente mayor en los individuos sin caries ${ }^{26}$.

\section{Conclusiones}

La caries dental es una enfermedad multifactorial, que precisa para su desarrollo de la interacción de factores como la resistencia del hués- 
ped, las relaciones microbianas, las características de la saliva y del sustrato, así como el tiempo para actuar. La evidencia proporcionada a nivel internacional sugiere que uno de los factores a considerar es la saliva cuyos componentes no solamente favorecen la prevención de caries, sino también pueden ser utilizados como herramienta de diagnóstico ${ }^{27}$.

Dada la importancia en la prevención de la caries y como una herramienta de diagnóstico conveniente, se recomienda que la función de las glándulas salivales sea determinada para cada paciente y seguida longitudinalmente para identificar cambios patológicos y permitir la iniciación de medidas preventivas.

\section{Bibliografia}

I. MEDINA, Myriam L., MERINO Luis A., GORODNER Jorge $O$. Utilidad de la saliva como fluido diagnóstico. Instituto de Medicina Regional - Universidad Nacional del nordeste. ISSN 0325 - 9528 Vol. I No I. 78, 88. 2004.

2. DENNY, $P$ AND COLS. Age- related changes in mucins from human whole saliva. J Dent Res.2000; 70 (10): I320 - I327.

3. GONZALEZ, M.; BANDERAS, J. A.; RAYA, C.; BAÉZ, A.; BELMONT, R. Quantification of lead, cadmium and chomium by sialochemistry. Salud Pública Mex. 1997 May-jun.; 39 (3): 179 - 186

4. AGUIRRE A.; TESTA-WEINTRAUB, LA.; BANDERAS, JA.; HARASZTHY, G.G. REDDY, M.S.; et. al. Sialochemistry: a diagnostic tool? Crit Rev. Oral Biol. Med 1993; 4 (3-4): 343 - 350.

5. SANZ, E. Valor de los anticuerpos salivares para la determinación de la seropositividad frente a sarampión, rubéola y parotiditis en niños y adultos. Anales Españoles de Pediatria. 1997; 47 (5): 499 - 504.

6. HERRERA, J. L; LYONS, M. F.; JOHNSON, L. F. Saliva: Its role in health and disease. J. Clin Gastroenterol. 1988; 10 (5): 69.

7. LA SALIVA COMO METODO DE DIAGNOSTICO PARA DETERMINAR LA INCIDENCIA DE CARIES EN ALUMNOS DE LA FACULTAD DE ESTUDIOS SUPERIORES IZTACALA. Laguna Cedillo Anaid Nicthe; Martínez Guerra David; Varela Martínez Fernanda; Villa Cano Tania; Zepeda Adrián.

8. ROMEROH.M.,HERNÁNDEZY.Modificaciones del $\mathrm{pH}$ y flujo salival con el uso de aparatología funcional tipo Bimler. Revista Latinoamericana de Ortodoncia y Odontopediatría [revista en
Internet]. Marzo 2009. [acceso 19 de marzo 2010];disponible en: http://www.ortodoncia.ws/ publicaciones/2009/art6.asp

9. LOYO MOLINA, Kenny, BALDA ZAVARCE, Rebeca, GONZALEZ BLANCO, Olga et al. Actividad Cariogenica y su Relación con el Flujo Salival y la Capacidad Amortiguadora de la Saliva.

10. Acta odontol. venez. [Online]. dic. 1999, Vol. 37, No 3 [citado 18 Agosto 20I I], p.10-17. Dis ponibleenWorldWideWeb:<http://www.scielo. org.ve/scielo.php?script=sci_arttext\&pid=SOOOI $63651999000300003 \&$ Ing=es\&nrm=iso>. ISSN $000 \mathrm{I}-6365$.

II. GONZÁLEZ, M.; LEDESMA, C.; BANDERAS, J. A. Saliva y cavidad bucal. Parte I: Glándulas salivales: mecanismos fisiológicos de la secreción salival. Pract Odontol 2004; 15 (6): 7 - I.

12. AGUIRRE A.; TESTA-WEINTRAUB, LA.; BANDERAS, J.A.; HARASZTHY, G.G. REDDY, M.S.; et. al. Sialochemistry: a diagnostic tool? Crit Rev. Oral Biol Med 1993; 4(3-4):343-350.

13. Toxicología Ambiental. Evaluación de riesgos y restauración ambiental (Disponible en http:// superfund.pharmacy.arizona.edu/toxamb/c2-33-5.html.)

14. DENNY, P AND COLS. Age- related changes in mucins from human whole saliva. J Dent Res.2000; 70 (10): 1320-1327

15. Guías Prácticas de Estomatología. Editorial Ciencias Médicas. La Habana, 2003. pp. 23 - 47.

16. OLIVERI, P.; MARI CAMPO, E;; ADAMI, J.; ZUBILLAGA M.; BOCCIO, J.; et. al. Identificación de la presencia de Helicobacter pylori ( $H p)$ en la cavidad oral mediante un método de análisis radiométrico en saliva. Diagnóstico. 2000 Enero; 
IX (88). (Disponible en http://www.diagnostico. com.ar./diagnos-tico/dia088/dhpo88.htm)

17. GONZALEZ, M.; BANDERAS, J. A.; RAYA, C.; BAÉZ, A.; BELMONT, R. Quantification of lead, cadmium and chomium by sialochemistry. Salud Pública Mex. 200 I May-Jun; 39 (3): 179 - 18.

18. JANÉ SANTAMARÍA, M.; VAREA CALDERÓN, V.; MUÑOZ ALMAGRO, M. C. Estudio de la placa dental en la infección por Helicobacter pylori. Anales Españoles de Pediatría. 1999; 50 (3): 244 - 246.

19. BANDERAS, J. A; GONZÁLEZ, M. Saliva y cavidad bucal. Parte II: Proteínas salivales: funciones biológicas en el mantenimiento de la homeostasis bucal. Pract Odontol 2004; 15 (7): 13 - 20.

20. KRASSE, B.O. Salivary examination. Caries risk Chicago: Quintessence Publishing Co., Inc. 1985:4I-44. Los nuevos métodos para la detección precoz del cáncer. La Tercera. Ciencia y Salud. Chile. (Disponible en http://www.tercera. $\mathrm{cl} /$ diario/2000/03/17/t 17.25.3a.CYS.NUE-VOS. html.)

21. MANDEL ID. Relation of saliva and plaque to caries. J Dent Res Supplement to $\mathrm{N}^{\circ} 2$. Vol 53, 1974.

22. FEJERSKOV O. Concepts Of. dental caries and their consequences for understanding the disease. Community Dent Oral Epidemiol 2005; 25:5-12.
23. WEYNE S. Cariología. En: Baritieri LN y colaboradores, editores. Operatoria Dental. Procedimientos Preventivos y Restauradores. Quintessence, 1999

24. FEATHERSTONE JBD. Prevention and reversal Of. Dental caries: role Of. Low level fluoride. Community Dent Oral Epidemiol 1999; 27:31-40.

25. ATEISHI, K.; TOH, Y.; MINAGAWA, H.; TASHIVO, H. Detección del Herpes Virus simple (HSV) en la saliva de 1000 pacientes por la reacción en cadena de la polimerasa (PCR) y la aislamiento del virus. J. Oral Pathol. Med. 1999; 23: 80 - 84.

26. Fox PC. Saliva composición and its importance in dental health. Compend Contin Educ Dent, Supple $N^{\circ} 13,2000$

27. LEESON CR, LEESON TS. Histología. 3ra. edición. Editorial Interamericana. 200I

28. PEREJOAN M. Sustitutos de la saliva. Revista Española de Estomatología, 1986; 326-332.

29. SREEBNY LM, VALDINI A, YU A. Xerostomia. Part II: Relationship to nonoral symptoms, drugs, and diseases Oral Surg Oral Med Oral Pathol 1981; 68:419-27.

30. EDGAR WM. Saliva: it's secretion, composición and functions. Br Dent J 1992; 172:305

3I. LAGERLÖF F, OLIVEBY A. Caries-Protective factors in saliva. Adv Dent Res 1994; 8(2): 229-238. 